\title{
Resonance Analysis of the UAV Rotor-arm part
}

\author{
Masahiko Mizui ${ }^{1}$, Ikuo Yamamoto ${ }^{2}$, Ryouga Ohsawa ${ }^{2}$ \\ ${ }^{I}$ Kyushu Kyouritu University, Common Education Center \\ ${ }^{2}$ The University of Kitakyushu, Dept. of Mechanical Systems Engineering
}

\begin{abstract}
The study of Aerial-photography by Unmanned Aerial Vehicle(UAV), becomes more and more important especially for disaster countermeasures. The Vibration from rotor part has an influence on sensors which measures flight parameters. It was found that resonant with natural frequency of arm part and vibration of rotor part gave rise to problems to the flight-stability of UAV. The sensor values from resonance will increase the amount of aircraft control. It is considered to cause overturn and hunting motion of the aircraft. Based on the thrust generated from the propeller, was determined natural frequency of the rotor-arm part by Rayleigh method. Design to understand the natural frequency of aircraft parts, it is important to avoid the resonance. Therefore, the risk of resonance verified with the frequency of rotor rotation speed of propeller.
\end{abstract}

Keywords: - UAV, flight-stability, Resonant, Natural Frequency, Rayleigh method

\section{INTRODUCTION}

The authors are developing small UAV and studying flight stabilization control. To understand the characteristics of the aircraft is important for the flight control. The authors are developed small-scale quadrotor [1] UAV shown in Fig.1 Attitude of the UAV the detection of air-frame angular velocity [2] are controlled by the PD control. The vibration from rotor part has an influence on sensors which measures flight parameters. The frequency of vibration changes proportion to the number of motor rotation. Cause of the vibration is unbalance of the propeller. Measures to unstable dynamic behavior [3], it is important to the design of the rotor.

The authors measured the resonant with natural frequency of arm part and rotor vibration. The resonant has an influence on sensors which measures flight parameters. The sensor values from resonance will increase the amount of aircraft control. It is considered to cause overturn and hunting motion of the aircraft. The natural frequency of the rotor-arm part is focused on preventable to resonance. The rotor-arm part simple model is consider to the cantilever [4] with concentrated load. Based on the thrust generated from the propeller, was determined natural frequency of the rotor-arm part by Rayleigh method [5]. Design to understand the natural frequency of aircraft parts, it is important to avoid the resonance [6]. Therefore, the risk of resonance verified with the frequency of rotor rotation speed of propeller.

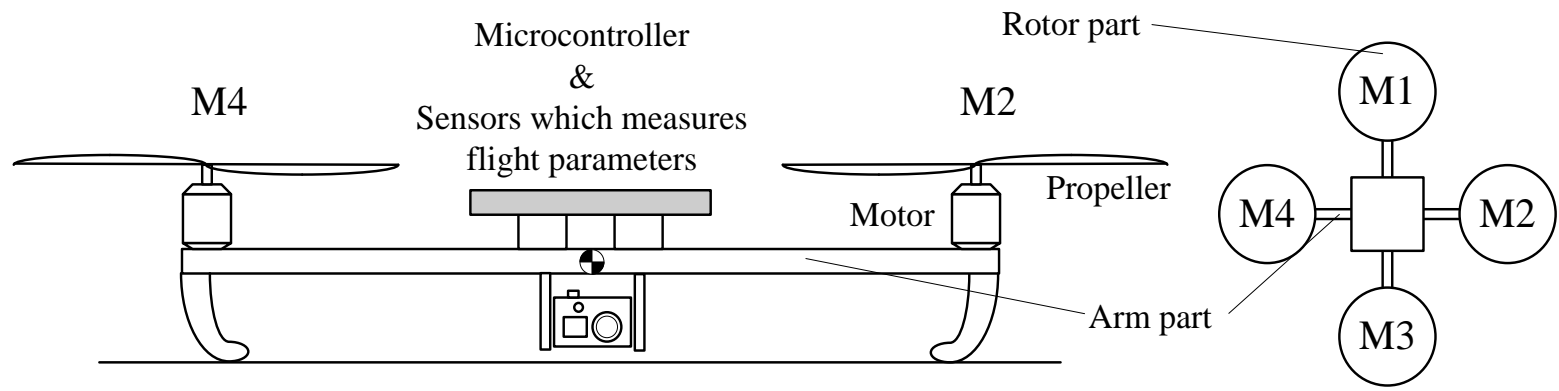

Fig.1 Quad type Unmanned Aerial Vehicle

\section{THE ROTOR-ARM PART MODEL}

The authors develop the experimental device that reproduces to situation of single rotor-arm part. The flexibility axis of pitch is prepared in the center of arm part. Arm part moves like seesaw. Propellers, motors, and amplifiers are arranged to the both sides ends of arm part, and both side weight is adjusted with them. The thrust is changed to lift of the mass. Loadcell measures the thrust of left-side propeller by leverage. Microcontroller and sensors are placed in the center of arm part, sensors measures gyro, acceleration, posture, etc. It was found that resonant with natural frequency of arm part and vibration of rotor part gave rise to problems to the flight-stability of UAV. Resonance is to influence to the sensor value of to measure the flight parameters. Therefore, the natural frequency of the rotor and the arm part calculate of the quadrotor UAV. Experimental device and simple rotor-arm part model is shown in fig.2. 


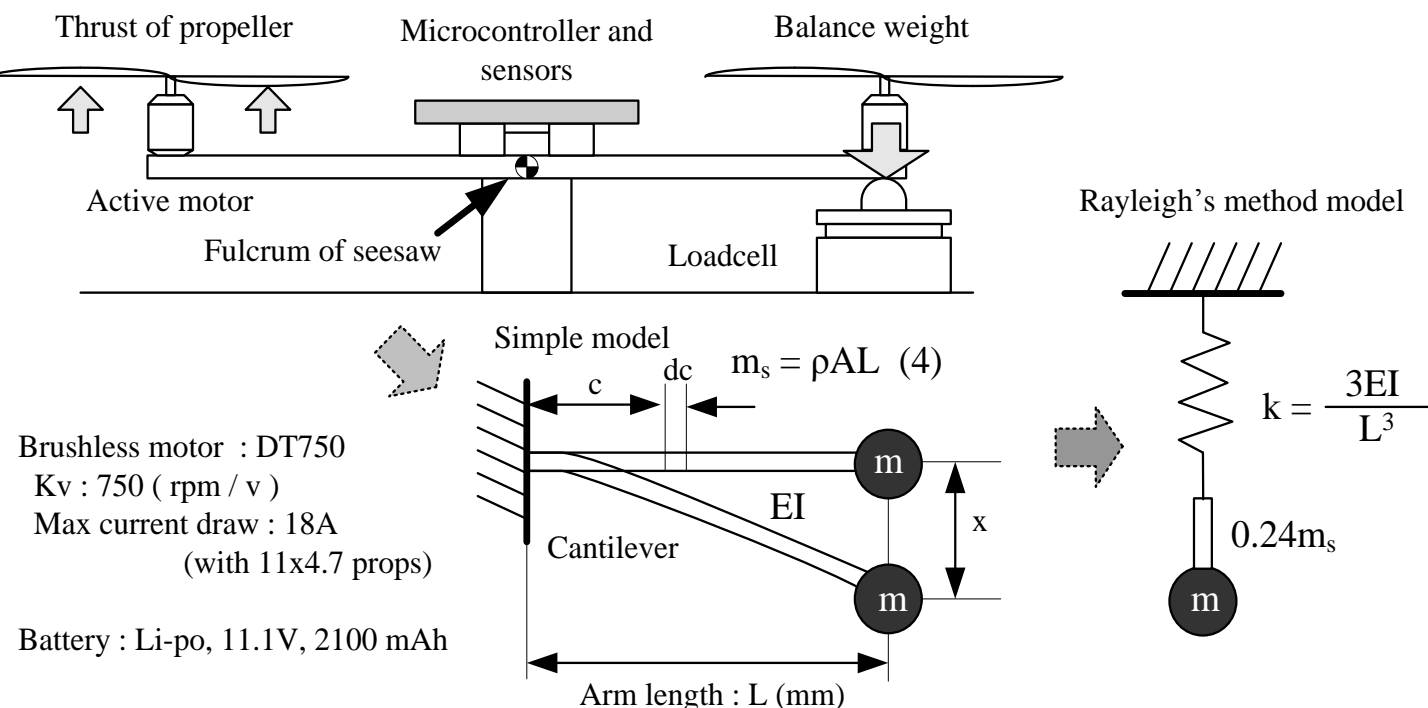

Fig.2 Experimental device and simple rotor - arm part model

The single rotor-arm part is same as cantilever (fixed end and free end).

The single rotor-arm part is same as cantilever (fixed end and free end). The rotor-arm part simple model is considered to the cantilever [4] with concentrated load. The natural frequency "Fn" is formulated from (1).

$$
\begin{aligned}
& F_{n}=\frac{\omega}{2 \pi}=\frac{1}{2 \pi} \sqrt{\frac{K}{M}} \\
& M=m+\frac{33}{140} m_{s}=m+0.24 m_{s}
\end{aligned}
$$

Rayleigh method collects the mass of the cantilever and concentrated load from all kinetic energy. Total mass "M" is formulated from (2). The arm part of a small UAV such as wood, aluminum, carbon material is selected. Yang modulus and density of arm material is shown in table.1.

Table.1 Yang modulus and density of arm material

\begin{tabular}{|l||c|c|}
\hline & Young modulus : E (GPa) & Density : $\rho\left(\mathrm{kg} / \mathrm{m}^{3}\right)$ \\
\hline Aluminum : A6063 & 70 & 2700 \\
\hline $\begin{array}{l}\text { Carbon fiber reinforced plastics } \\
\text { (CFRP) }\end{array}$ & 140 & 1600 \\
\hline Wood : White cedar & 9 & 440 \\
\hline
\end{tabular}

Cross-sectional shape of the arm, circle, circle pipe, square, square pipe, and square timber is selected. The moment of inertia of area "I" in useful type of UAV is shown in fig.3, and formulated from (5 - 8). This model is simplified of relationship between mass and the spring. Spring constant "k" can adjust in length and material of the arm. The authors investigated by balance or non-balance propeller that relationship to number of revolutions between thrust and current. The mass of concentrated load " $\mathrm{m}$ " is used from the propeller thrust of the experimental results. 
Moment of inertia of area : I

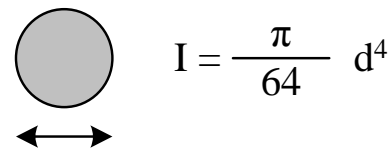

Diameter : $\mathrm{d} \mathrm{mm}$

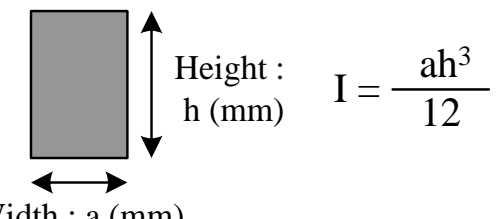

Width : a (mm)
Thickness : $\mathrm{t}$ mm

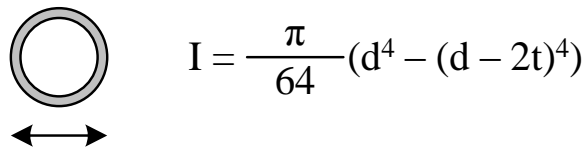

Diameter : $\mathrm{d} \mathrm{mm}$

Thickness : $\mathrm{t}(\mathrm{mm})$

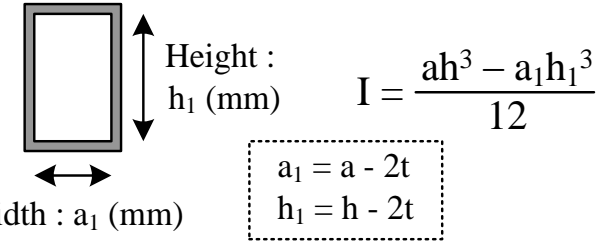

Fig.3 Arm cross-sectional shapes and moment of inertia of area

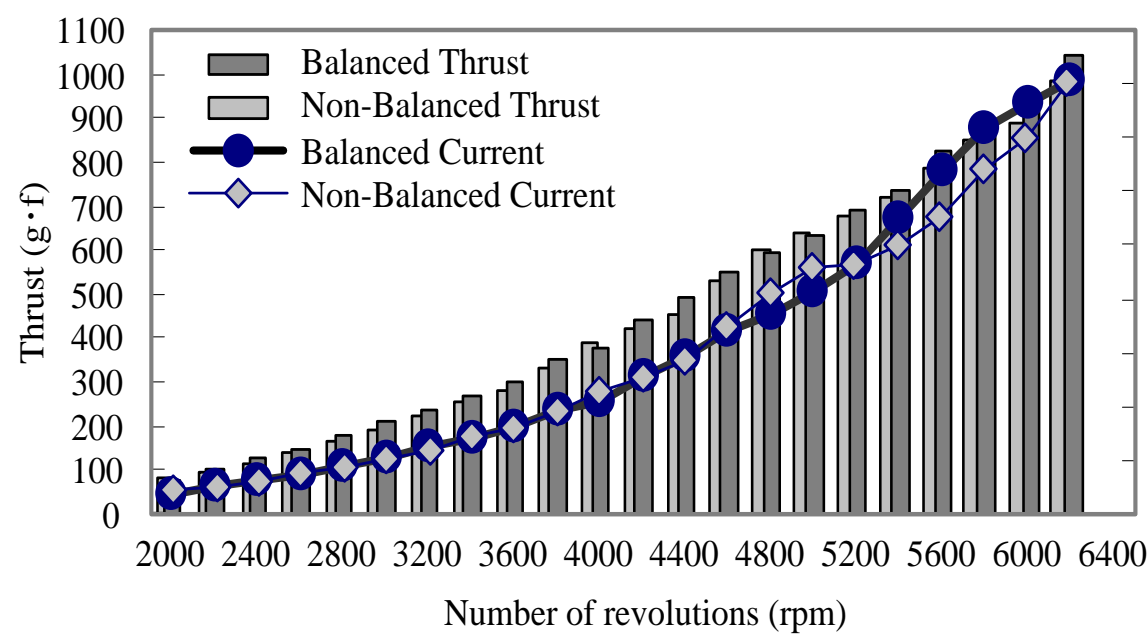

18.00

16.00

14.00

12.00

10.00

8.00

6.00

4.00

2.00

Fig.4 Type "11x4.7" thrust and current

III. THE NATURAL FREQUENCY OF ARM PART

Based on the thrust generated from the propeller, was determined natural frequency "Fn" of the rotorarm part by Rayleigh method. The compare rotation number "Rn" is 60 times for natural frequency "Fn". The Cantilever has a free end. Therefore, the resonance is generated by the odd multiples of natural frequencies.

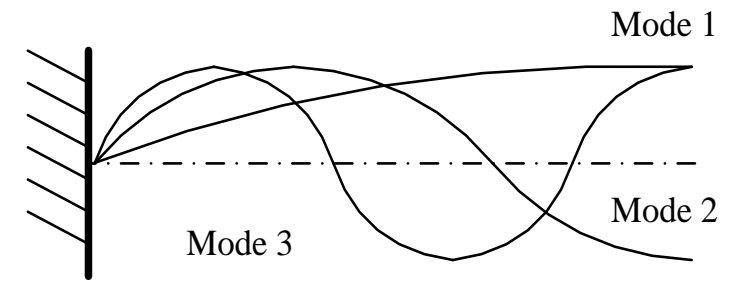
Mode $1: \lambda_{1}=1 / \mathrm{Fn}$
Mode $2: \lambda_{2}=3 \times \lambda_{1}$
Mode $3: \lambda_{3}=5 \times \lambda_{1}$
Mode $\mathrm{n}: \lambda_{\mathrm{n}}=(2 \mathrm{n}-1) \times \lambda_{1}$

Fig.5 Resonant mode numbers of cantilever

The natural frequency multiple data F1 $\sim$ F12 are computed from the thrust occurred in the number of revolutions of propeller. Natural frequency was calculated under the same conditions as the experiment in fig.4 ("11x4.7" trade edition propeller, wood: white cedar, square timber 9×9mm, arm length: $0.438 \mathrm{~m}$ ). Table 2 shows the part of calculation result. The smaller the absolute value of the difference between the "Rn" and the rotor rotational speed "Crisis rate", means that the easy-to-resonance. Low mode1 value of natural frequency is easy to resonate. So, multiple is narrow step, because. The factors of determine the natural frequencies of the arm is the arm length, material, and moment of inertia. In particular, the highest usage of rotor rotational speed is near the hovering thrust in the UAV. It is necessary to design to avoid resonance at near hovering number of revolutions. 
Resonance Analysis of the UAV Rotor-arm part

Table. 2 Resonance risk of the rotor rotational speed

\begin{tabular}{|r|r|r|r|r|r|r|r|r|r|r|}
\hline $\begin{array}{r}\text { Rotor } \\
(\text { RPM })\end{array}$ & $\begin{array}{l}\text { Thrust } \\
(\mathrm{g} \cdot \mathrm{f})\end{array}$ & R1 & R2 & R3 & R4 & R5 & R6 & R7 & R8 & $\begin{array}{l}\text { Crisis } \\
\text { rate }\end{array}$ \\
\hline 2000 & 80 & 646 & $\mathbf{1 9 3 9}$ & 3231 & 4524 & 5816 & 7109 & 8401 & 9694 & $\mathbf{6 1}$ \\
\hline 2200 & 92 & 605 & $\mathbf{1 8 1 6}$ & 3026 & 4237 & 5447 & 6658 & 7868 & 9078 & 384 \\
\hline 2400 & 113 & 549 & 1647 & $\mathbf{2 7 4 5}$ & 3843 & 4941 & 6039 & 7137 & 8236 & -345 \\
\hline 2600 & 136 & 502 & 1507 & $\mathbf{2 5 1 2}$ & 3517 & 4522 & 5527 & 6532 & 7537 & $\mathbf{8 8}$ \\
\hline 2800 & 162 & 462 & 1386 & 2309 & $\mathbf{3 2 3 3}$ & 4157 & 5080 & 6004 & 6928 & -433 \\
\hline 3000 & 188 & 430 & 1289 & 2149 & $\mathbf{3 0 0 8}$ & 3868 & 4727 & 5586 & 6446 & $\mathbf{- 8}$ \\
\hline 3200 & 216 & 402 & 1205 & 2008 & $\mathbf{2 8 1 2}$ & 3615 & 4418 & 5222 & 6025 & 388 \\
\hline 3400 & 250 & 374 & 1122 & 1870 & 2618 & $\mathbf{3 3 6 6}$ & 4114 & 4862 & 5610 & $\mathbf{3 4}$ \\
\hline 3600 & 275 & 357 & 1071 & 1785 & 2499 & 3212 & $\mathbf{3 9 2 6}$ & 4640 & 5354 & -326 \\
\hline 3800 & 321 & 331 & 993 & 1654 & 2316 & 2978 & $\mathbf{3 6 3 9}$ & 4301 & 4963 & 161 \\
\hline 4000 & 375 & 306 & 919 & 1532 & 2145 & 2758 & 3371 & 3984 & 4597 & $\mathbf{1 6}$ \\
\hline 4200 & 405 & 295 & 885 & 1475 & 2066 & 2656 & 3246 & 3836 & $\mathbf{4 4 2 6}$ & -226 \\
\hline 4400 & 440 & 283 & 850 & 1416 & 1983 & 2549 & 3116 & 3682 & $\mathbf{4 2 4 9}$ & 151 \\
\hline 4600 & 512 & 263 & 788 & 1314 & 1840 & 2365 & 2891 & 3417 & 3942 & 132 \\
\hline
\end{tabular}

\section{COMPARISON WITH THE RESULTS OF SENSOR WHICH MEASURE FLIGHT PARAMETERS}

Fig.6 shows the results of sensor which measure flight parameters.

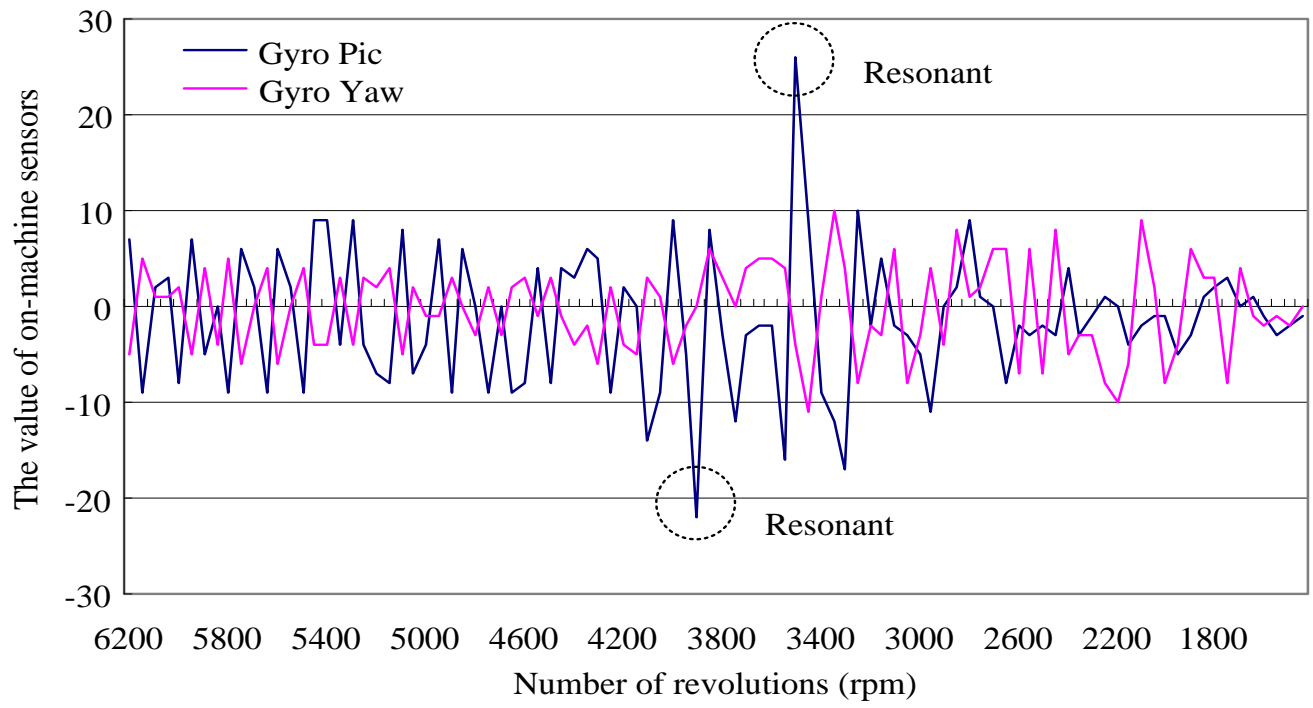

Fig.6 Sensors data in type "11x4.7" trade edition propeller

Sensors measure cycle is period of about $10 \mathrm{~ms}$. The authors were measured to -200rpm step from 6400rpm. The Graph values are average ten points max and min values for each rotational speed. There is a point sensor values greatly disturbed in Fig.6. At those points the rotor and the arm on the experimental device that was vibrated together. Therefore, the authors can predict the risk of specific resonance frequency calculations using the Rayleigh method.

\section{DIFFERENCES OF MATERIALS}

A similar calculation do in table 2 and square timbers pipe used in aluminum and carbon to small UAV. Differences of materials are shown in table.3. Crisis rate is stressed the value of 50 or below. In the case of aluminum and carbon, interval of the multiple is wide by Young's modulus. The arm length "L" is also significantly affects the result. Changes in the design parameter can be carried out in a prediction of the resonance. 
Table.3 Differences of materials

\begin{tabular}{|c|c|c|c|c|c|c|c|c|c|c|}
\hline \multirow[b]{2}{*}{$\begin{array}{l}\text { Rotor } \\
\text { (RPM) }\end{array}$} & \multirow[b]{2}{*}{$\begin{array}{l}\text { Thrust } \\
\left(\mathrm{g}^{\cdot} \mathrm{f}\right)\end{array}$} & \multicolumn{3}{|c|}{ Wood: White cedar } & \multicolumn{3}{|c|}{ Aluminum : A6063 } & \multicolumn{3}{|c|}{ CFRP } \\
\hline & & $\begin{array}{l}\text { Resonance } \\
\text { RPM }\end{array}$ & $\begin{array}{l}\text { Mode } \\
\text { number }\end{array}$ & $\begin{array}{l}\text { Crisis } \\
\text { rate }\end{array}$ & $\begin{array}{l}\text { Resonance } \\
\text { RPM }\end{array}$ & $\begin{array}{l}\text { Mode } \\
\text { number }\end{array}$ & $\begin{array}{l}\text { Crisis } \\
\text { rate }\end{array}$ & $\begin{array}{l}\text { Res onance } \\
\text { RPM }\end{array}$ & $\begin{array}{l}\text { Mode } \\
\text { number }\end{array}$ & $\begin{array}{l}\text { Crisis } \\
\text { rate }\end{array}$ \\
\hline 2000 & 80 & 1939 & $R_{2}$ & 61 & 1387 & R1 & 613 & 1369 & R1 & 631 \\
\hline 2200 & 92 & 1816 & $R_{2}$ & 384 & 1323 & R1 & 877 & 1292 & RI & 908 \\
\hline 2400 & 113 & 2745 & $R 3$ & -345 & 1229 & R1 & 1171 & 3548 & $R 2$ & -1148 \\
\hline 2600 & 136 & 2512 & $\mathrm{R} 3$ & 88 & 3440 & R2 & -840 & 3270 & $R 2$ & -670 \\
\hline 2800 & 162 & 3233 & R4 & -433 & 3212 & $R 2$ & -412 & 3023 & $R 2$ & -223 \\
\hline 3000 & 188 & 3008 & R4 & -8 & 3024 & $R_{2}$ & -24 & 2824 & $\mathrm{R} 2$ & 176 \\
\hline 3200 & 216 & 2812 & R5 & 388 & 2854 & $R_{2}$ & 346 & 2649 & $\mathrm{R} 2$ & 551 \\
\hline 3400 & 250 & 3366 & R6 & 34 & 2682 & $R_{2}$ & 718 & 4124 & $R 3$ & -724 \\
\hline 3600 & 275 & 3926 & R6 & -326 & 4290 & R3 & -690 & 3944 & $\mathrm{R} 3$ & -344 \\
\hline 3800 & 321 & 3639 & R? & 161 & 4008 & $\mathrm{R} 3$ & -208 & 3665 & R3 & 135 \\
\hline 4000 & 375 & 3984 & $R 8$ & 16 & 3739 & $\mathrm{R3}$ & 261 & 3404 & $R 3$ & 596 \\
\hline 4200 & 405 & 4426 & R8 & -226 & 3611 & $\mathrm{R} 3$ & 589 & 4592 & R4 & -392 \\
\hline 4400 & 440 & 4249 & RS & 151 & 4867 & $\mathrm{R} 4$ & -467 & 4413 & $\mathrm{R} 4$ & -13 \\
\hline 4600 & 512 & 4468 & $R 9$ & 132 & 4539 & R4 & 61 & 4102 & R4 & 498 \\
\hline 4800 & 583 & 4683 & R10 & 117 & 4273 & R4 & 527 & 4952 & R5 & -152 \\
\hline 5000 & 615 & 5040 & R11 & -40 & 5359 & R5 & -359 & 4824 & $\mathrm{R} 5$ & 176 \\
\hline 5200 & 654 & 5355 & R12 & -155 & 5206 & $\mathrm{R} 5$ & -6 & 4682 & R.5 & 518 \\
\hline 5400 & 750 & - & - & - & 4880 & R.5 & 520 & 5352 & R6 & 48 \\
\hline 5600 & 760 & - & - & - & 5927 & R6 & -327 & 5318 & R6 & 282 \\
\hline 5800 & 820 & - & - & - & 5717 & $\mathrm{R} 6$ & 83 & 6055 & R7 & -255 \\
\hline 6000 & 856 & - & - & - & 5601 & R6 & 399 & 5929 & R7 & 71 \\
\hline 6200 & 950 & - & - & - & 6297 & $R 7$ & -97 & 6500 & $\mathrm{RS}$ & -300 \\
\hline
\end{tabular}

\section{Conclusion}

Based on the thrust generated from the propeller, was determined natural frequency of the rotor-arm part by Rayleigh method. The risk of resonance verified with the frequency of rotor rotation speed of propeller. Compared with the experimental results in the experimental device, it was confirmed that the resonance point and the calculated values are consistent. The authors can predict the risk of specific resonance frequency calculations using the Rayleigh method. Design to understand the natural frequency of aircraft parts, it is important to avoid the resonance. It is necessary to design to avoid resonance at near hovering number of revolutions.

\section{REFERENCES}

[1] G.Hoffmann, H.Huang, S.Waslander, and C.Tomlin, Quadrotor helicopter flight dynamics and control: Theory and experiment, Proceedings of the AIAA Guidance, Navigation, and Control Conference, 2007, AIAA 2007-6461.

[2] A.Tayebi,S.McGilvray, Attitude Stabilization of a VTOL Quadrotor Aircraft, IEEE Trans. on CST 14(3), 562-571, 2006

[3] P.Corke, J.Roberts, Towards Dynamically-Favourable Quad-Rotor Aerial Robots, In Proceedings of the Australasian Conference on Robotics and Automation, Canberra, 2004

[4] T.Funada, T.Funada, Update of Education Materials in the Elastic Theory for Engineering Education : Oscillation analysis of EulerBernoulli Beam, Numazu College of Technology research 40,83-92,2006-01-13

[5] M.Kataoka, S.Ohno, E.Marui, Calculation of Natural Frequencies of Bending Vibration of Straight Rod with Additional Mass and Subjected to Axial Compression, and Estimation of Axial Force, JSME international journal. Ser. C, Dynamics, control, robotics, design and manufacturing Vol. 37 (1994) No. 1 P 21-27

[6] S.Mitsuta, E.Okawa, K.Seto, H.Ito, Active Vibration Control of Structures Arranged in Parallel, JSME international journal. Ser. C, Dynamics, control, robotics, design and manufacturing Vol. 37 (1994) No. 3 P 436-443 